Study of DNA in "Glasslike State" by Atomic Force Microscopy: Importance of Substrates

This content has been downloaded from IOPscience. Please scroll down to see the full text. 2006 Jpn. J. Appl. Phys. 452345

(http://iopscience.iop.org/1347-4065/45/3S/2345)

View the table of contents for this issue, or go to the journal homepage for more

Download details:

IP Address: 128.178.195.111

This content was downloaded on 20/07/2014 at 14:02

Please note that terms and conditions apply. 
(C) 2006 The Japan Society of Applied Physics

\title{
Study of DNA in "Glasslike State" by Atomic Force Microscopy: Importance of Substrates
}

\author{
Susana Tobenas*, Eva Bystrenova ${ }^{1}$, Aleksandra RAdenOvic ${ }^{2}$, \\ Giovanni Di SANTO and Giovanni DiETLER \\ Institute of Complex Matter Physics, EPFL, CH-1015 Lausanne, Switzerland \\ ${ }^{1}$ Institute for Nanostructured Material Studies, CNR, Via P. Gobetti 101,40129 Bologna, Italy \\ ${ }^{2}$ Physics Department, University of California, Berkeley, CA 94720, U.S.A.
}

(Received July 4, 2005; accepted September 26, 2005; published online March 27, 2006)

\begin{abstract}
An atomic force microscopy (AFM) system operating at low temperatures and under ultra high vacuum (UHV) conditions is presented. The AFM system uses the laser beam deflection method to detect the cantilever deflection. The system was completely developed in our laboratory for studying biological samples [A. Radenovic et al.: Rev. Sci. Instrum. 74 (2003) 1022]. To study DNA by AFM requires a substrate on which the DNA can be adsorbed from an aqueous solution. Images of DNA at room temperature and at low temperatures on three different surfaces are presented, including the first images of DNA on the treated HOPG obtained at $82 \mathrm{~K}$. The importance of the hydrophobic degree of the substrate for imaging DNA at low temperatures is discussed. [DOI: 10.1143/JJAP.45.2345]
\end{abstract}

KEYWORDS: cryo-AFM, DNA, hydrophobic substrates

\section{Introduction}

Atomic force microscopy (AFM), first developed by Binnig et al., ${ }^{1)}$ has become a powerful tool in biology. It can provide three-dimensional images of biological specimens in ambient, liquid or gas environments. Unlike other techniques, AFM can image samples with minor preparation, e.g., without staining and coating and over a large range of temperatures. The good resolution (in the nanometer range) permits imaging samples such as DNA molecules with detail. However, thus far, high-resolution imaging of DNA or evidence of DNA helicity has been only achieved in a very few cases. ${ }^{2)}$ More recent studies of DNA by non contact AFM under ultra high vacuum conditions are promising to obtain higher resolution images. ${ }^{3-5)}$

As demonstrated by many studies, biomolecular complexes are too soft for achieving high-resolution imaging at room temperature in contact mode. Indeed the deformation of flexible biomolecular structures is very large under the AFM tip and the cantilever also undergoes thermal motion. All these effects reduce the instrument resolution. To overcome these limitations, measurements on biological materials should be performed at low temperatures.

Therefore we have designed a low temperature AFM (cryo AFM) with in situ tip/sample exchange for studying biological samples under UHV. A detailed description of the instrument was previously reported. ${ }^{6}$

In this paper, we present results obtained at low temperatures under UHV conditions.

\section{Experimental Methods and Results}

The driving force for studying DNA lies in the potential to attain high resolution with AFM imaging. Thus far, nearly all AFM measurements on DNA have shown that DNA presents a reduced height, in the range of $\left.1-1.3 \mathrm{~nm},{ }^{7,8}\right)$ compared with X-ray crystallographic data. ${ }^{9)}$ However, at temperatures close to $200 \mathrm{~K}$ or lower, most of macromolecules become much stiffer than at room temperature ${ }^{10)}$ their structural rigidity are increased as well as their

*E-mail address: susana.tobenas@epfl.ch adhesion to the substrate being improved. We extended the different DNA adsorption techniques known to work well under ambient conditions towards low-temperature applications.

Freshly cleaved mica and graphite (highly ordered phyrolityc graphite; HOPG) substrates were used. To avoid any charging effect and long-distance electrostatic repulsion between the cantilever and the substrate, both, the metallic sample holder and the tip are grounded. Since the graphite is bulk-conductive and since the conduction on the surface of a mica-DNA system takes place probably through the surface water layer, the proper grounding of the sample holder and of the AFM tip totally cancels any charging effect and makes any large adhesion effect disappear.

All images were obtained in contact mode with uncoated silicon cantilevers (MikroMasch), nominal spring constant $0.12 \mathrm{~N} / \mathrm{m}$ and using a setpoint of $10 \mathrm{mV}$ which corresponds to a force of $700 \mathrm{pN}$ at room temperature and consequently to $300 \mathrm{pN}$ at low temperatures.

Linear and circular (plasmid) DNAs have been investigated in our system. The plasmid's protocol of purification is described in ref. 11. Lambda mix linear DNA has been purchased from MBI FERMENTAS (St. Leon-Rot, Germany).

The DNA molecules should be adsorbed on substrates which have flat surfaces on the molecular level such as mica or HOPG. The surface characteristics of these substrates are different and therefore they require different deposition protocols.

\subsection{Adsorption of DNA on mica in the presence of divalent cations}

Mica, the most common substrate for AFM, consists of tetrahedral double sheets of $(\mathrm{Si} / \mathrm{Al})_{2} \mathrm{O}_{5}$ electrostatically linked by potassium ions. This electrostatic interaction plays an important role for adsorbing and binding DNA. To improve the method of ionic treatment of mica, ${ }^{12}$ as suggested earlier for sample preparation used in transmission electron microscopy, one can use divalent cations (e.g., $\mathrm{Mg}^{2+}, \mathrm{Zn}^{2+}$, etc.) to increase the mica affinity to DNA.

DNA molecules (plasmids and linear) were prepared in a 


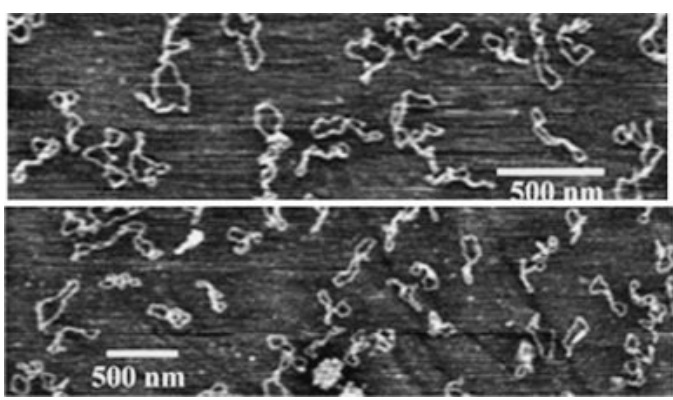

Fig. 1. Images of DNA plasmids deposited on mica surface in presence of divalent cations: (top) ambient conditions and (bottom) at $200 \mathrm{~K}$.

buffer solution of $10 \mathrm{mM}$ Tris- $\mathrm{HCl}$, ph 7.6, $10 \mathrm{mM} \mathrm{MgCl}_{2}$; having a final DNA concentration of $1 \mu \mathrm{g} / \mathrm{ml}$. A droplet of this sample was then placed onto the appropriate freshly cleaved mica for $10 \mathrm{~min}$ at room temperature, rinsed with nanopure (ultra high quality) water and blown dry with clear air.

Figure 1 shows images of the DNA plasmids obtained in our system at different temperatures. The lowest temperature at which we were able to obtain high-resolution images of DNA plasmids was $200 \mathrm{~K} .^{6)}$ Images obtained in the contact mode with cryo AFM at $200 \mathrm{~K}$ show improvement in the height of DNA. While the average height of DNA at room temperature is $1 \mathrm{~nm}$, it increases to $2.3 \mathrm{~nm}$ at $200 \mathrm{~K}$ as previously reported. ${ }^{6}$

Nevertheless, at temperatures near $80 \mathrm{~K}$, the surface roughness increases up to $4-5 \mathrm{~nm}$ making the imaging of DNA impossible [see Fig. 2 (middle)]. Then, if the sample temperature is allowed to increase gradually, imaging of DNA is recovered at above $180 \mathrm{~K}$ [see Fig. 2 (bottom)].

The formation of a water layer on the hydrophilic mica surface was addressed previously in the literature. ${ }^{7,13)}$ This could be one of the reasons for the high adhesion observed at that temperature, as shown in Fig. 6(a). This fact could strongly impair the imaging of DNA on mica at these temperatures. As a consequence, the proper choice of a hydrophobic substrate for imaging DNA at low temperatures is essential.

\subsection{Adsorption of DNA on the functionalized (APTES) mica surface}

Lyubchenko et al. ${ }^{14)}$ developed a different method of binding DNA to the mica surface. They modified the negatively charged surface using an amino-terminal silane making it strongly positively charged in aqueous solution. The mica modified in such a way was called AP-mica, from the name of the silane used in the reaction: 3-aminopropyltriethoxysilane (APTES).

For AFM imaging, $\lambda$-phage DNA molecules were prepared in a buffer solution of $10 \mathrm{mM}$ Tris- $\mathrm{HCl}$, ph 7.6, $1 \mathrm{mM}$ EDTA, having a final DNA concentration of $1 \mu \mathrm{g} / \mathrm{ml}$. The substrates (freshly cleaved mica) were positively charged by exposing them to 3-aminopropyltriethoxy silane (APTES) vapors for $2 \mathrm{~h}$ at room temperature in a dry atmosphere. ${ }^{14)}$ A $10 \mu$ l drop of a DNA solution was deposited onto the substrate surface for $10 \mathrm{~min}$ and then rinsed with ultra pure water. The sample was finally blown dry with clean air.
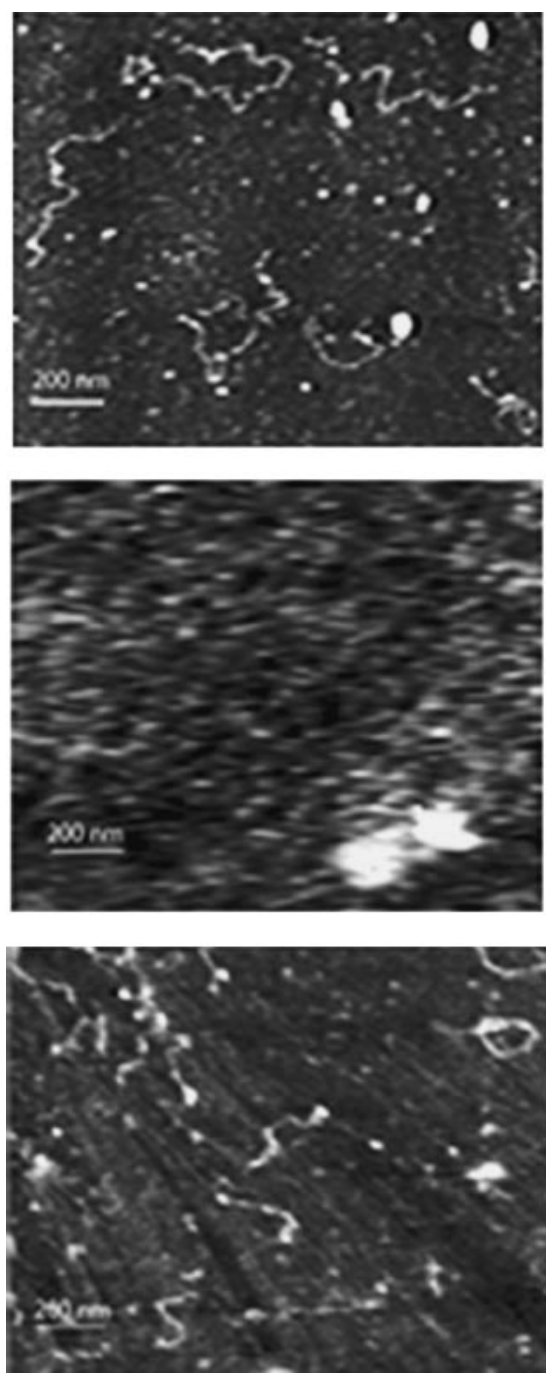

Fig. 2. Short fragments of $\lambda$-DNA deposited on mica surfaces in presence of divalent cations: (top) ambient conditions, (middle) at $80 \mathrm{~K}$ and (bottom) at $200 \mathrm{~K}$ while the system was being heated.

It is known that silanized surface of mica is more hydrophobic than the freshly cleaved one (indeed this effect can be easily verified by contact angle measurements) as clearly shown on Fig. 6(b).

This higher hydrophobicity of AP-mica was confirmed by the measurements with our cryo-AFM system, since the above mentioned roughness measured on the sample surface was only in the range of $1-1.5 \mathrm{~nm}$ at $82 \mathrm{~K}$. Most probably due to a thinner, but still present frozen water layer, under these conditions scanning of DNA was still very difficult. The DNA images obtained in contact mode with our cryoAFM system at room temperature and at $200 \mathrm{~K}$ on AP-mica are shown on Fig. 3.

\subsection{Adsorption of DNA on HOPG surface}

Another substrate commonly used in scanning tunneling microscopy is graphite. It seems suitable for biological imaging and it is strongly hydrophobic. Proper grounding of graphite can be realized very easily in comparison with mica. Therefore, we have choosen this substrate for imaging DNA at low temperatures although the process of DNA adsorption to graphite is more complicated than in the case of mica. 

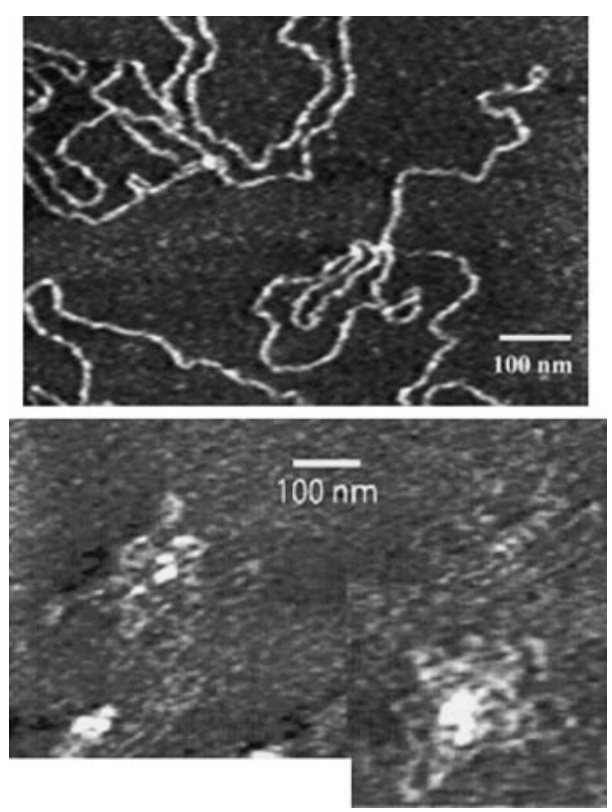

Fig. 3. Images of $\lambda$-DNA deposited on AP-mica (top) ambient conditions and (bottom) at $200 \mathrm{~K}$.

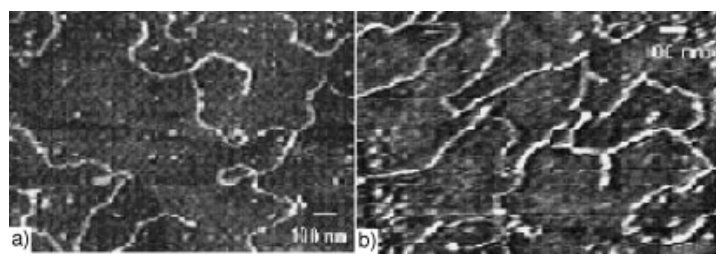

Fig. 4. Images of $\lambda$-DNA on HOPG (a) ambient conditions and (b) at $200 \mathrm{~K}$.
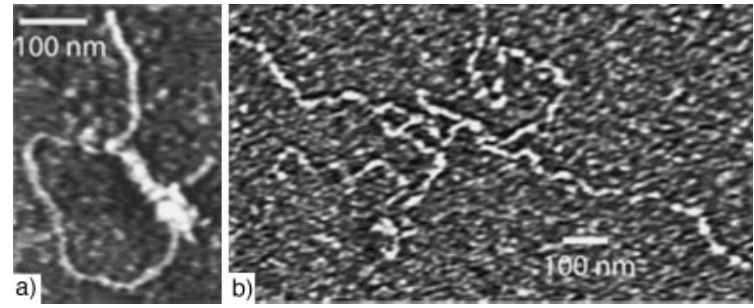

Fig. 5. (a) Plasmid DNA on HOPG at $135 \mathrm{~K}$, (b) detail of $\lambda$-DNA on HOPG at $82 \mathrm{~K}$.

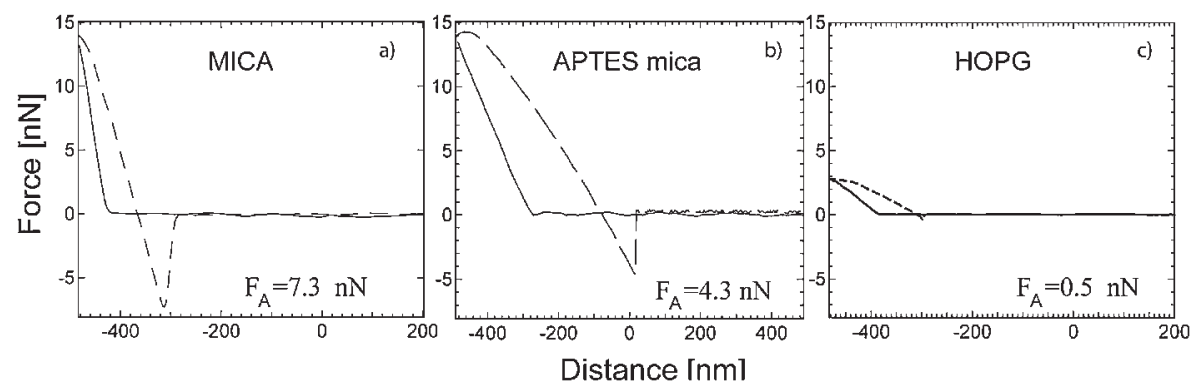

Fig. 6. Typical force-distance curves of uncoated silicon cantilevers with spring constant $0.12 \mathrm{~N} / \mathrm{m}$ measured at $82 \mathrm{~K}$ on different substrates: (a) mica, (b) AP-mica and (c) treated HOPG.

It is well documented ${ }^{15)}$ that the HOPG surface treated by glow discharge technique possesses polar surface groups. The existence of polar groups renders the HOPG surface temporarily hydrophilic. The surface of HOPG was treated for $10-30 \mathrm{~s}$ in oxygen plasma. Then hydrophilic and negatively charged HOPG allows easy spreading of the DNA suspension. With a subsequent magnesium acetate or magnesium chloride treatment, the surface becomes hydrophilic and positively charged (as in case of mica).

To deposit DNA molecules on HOPG after the glow discharge treatment we followed the same procedure described above for the adsorption on mica in the presence of divalent cations. DNA molecules adhered better to such surface allowing contact-mode AFM imaging.

After a brief time, the substrate recovers its hydrophobicity, allowing the imaging at low temperature and in UHV without a contamination layer. Low adhesion forces on HOPG were measured as shown in Fig. 6(c).

The drawback of this method is the high average roughness of the substrate due to the glow discharge method. The measured roughness on the HOPG surface was found to be in the range of $0.2-0.5 \mathrm{~nm}$. In Fig. 4 images of linear DNA obtained in contact mode with cryo-AFM at room temperature and at $200 \mathrm{~K}$ and are shown. The recovered hydrophobicity of HOPG after treatment was confirmed by measurements at $82 \mathrm{~K}$ where imaging of DNA was possible (Fig. 5).

\section{Conclusions}

Different techniques for the adsorption of DNA onto a suitable surface for cryo-AFM imaging were investigated. Divalent ions bridging freshly cleaved mica, modification of the mica substrate using a positively charged silane and modification of graphite by glow discharge technique allowed a good imaging of the DNA under ambient conditions. We showed the importance of the different degree of hydrophobicity of the substrate for achieving highresolution images at low temperatures and under UHV conditions. The first images of linear DNA on HOPG obtained at $82 \mathrm{~K}$ are presented.

\section{Acknowledgments}

This work was partially funded by the Swiss National Science Foundation under Grants Nos. 2000-065160.01 and 21-61397.00. 
1) G. Binnig, C. F. Quate and C. Gerber: Phys. Rev. Lett. 56 (1986) 930.

2) H. G. Hansma, D. E. Laney, M. Bezanilla, R. L. Sinsheimer and P. K. Hansma: Biophys. J. 68 (1995) 1672.

3) Y. Maeda, T. Matsumoto and T. Kawai: Appl. Surf. Sci. 140 (1999) 400.

4) T. Uchihashi, M. Tanigawa, M. Ashino, Y. Sugawara, K. Yokoyama, S. Morita and M. Ishikawa: Langmuir 16 (2000) 1349.

5) Y. Maeda, T. Matsumoto, H. Tanaka and T. Kawai: Jpn. J. Appl. Phys. 38 (1999) L1211.

6) A. Radenovic, E. Bystrenova, L. Libioulle, M. Taborelli, J. A. DeRose and G. Dietler: Rev. Sci. Instrum. 74 (2003) 1022.

7) H. G. Hansma, I. Revenko, K. Kim and D. E. Laney: Nucl. Acids Res. 24 (1996) 713.

8) Z. Shao, J. Yang and A. P. Somlyo: Annu. Rev. Cell. Dev. Biol. 11
(1995) 241.

9) J. D. Watson and F. H. C. Crick: Nature 171 (1953) 737.

10) I. E. T. Iben, D. Braunstein, W. Doster, H. Frauenfelder, M. K. Hong, J. B. Johnson, S. Luck, P. Ormos, A. Schulte, P. J. Steinbach, A. H. Xie and R. D. Young: Phys. Rev. Lett. 62 (1989) 1916.

11) V. Viglasky, M. Antalik, J. Adamcik and D. Podhradsky: Nucl. Acids Res. 28 (2000) e51.

12) M. Bezanilla, S. Manne, D. E. Laney, Y. L. Lyubchenko and H. G. Hansma: Langmuir 11 (1995) 655.

13) S. Park and G. Sposito: Phys. Rev. Lett. 89 (2002) 085501.

14) Y. Lyubchenko, L. Shlyakhtenko, R. Harrington, P. Oden and S. Lindsay: Proc. Natl. Acad. Sci. U.S.A. 90 (1993) 2137.

15) J. V. Zoval, P. R. Biernacki and R. M. Penner: Anal. Chem. 68 (1996) 1585. 